\title{
From Monoculture to Norfolk System: How the Number of Crops in Rotation Can Influence the Biodiversity of Arbuscular Mycorrhiza Assemblages in the Soil
}

\author{
Franco Magurno1, Zita Sasvári', Lorenzo Barchi², Katalin Posta1 \\ ${ }^{1}$ Microbiology and Environmental Toxicology Group, Institute of Plant Protection, Szent István University, \\ Gödöllö, Hungary \\ ${ }^{2}$ DISAFA (Dipartimento di Scienze Agrarie, Forestali e Alimentari), Plant Genetics and Breeding, University of \\ Torino, Torino, Italy \\ Email: Posta.Katalin@mkk.szie.hu
}

Received 26 September 2014; revised 28 October 2014; accepted 15 November 2014

Copyright $@ 2014$ by authors and Scientific Research Publishing Inc.

This work is licensed under the Creative Commons Attribution International License (CC BY). http://creativecommons.org/licenses/by/4.0/

(c) ()

\begin{abstract}
Given the attention drawn since several decades by arbuscular mycorrhizal fungi (AMF) as potential biological alternatives to chemicals in a low-input agriculture, much effort has been spent in the investigation of mechanisms influencing the dynamics inside AMF communities. In the present study we evaluated the influence of different crop rotations on the AMF soil community, after a 50 y long-term field experiment established at Martonvásár, Hungary. Four types of crop rotation were chosen for sampling: corn monocropping, corn-alfalfa, corn-wheat, and corn-spring barleypeas-wheat. Community composition of AMF in soil was analyzed with a molecular approach amplifying a portion of $28 \mathrm{~S}$ rDNA. The crop rotation practice didn't show an influence on identity of the species composing AMF assemblages, but on the other hand seemed to affect positively the true diversity, defined as number of MOTUs present in the communities.
\end{abstract}

\section{Keywords}

Arbuscular Mycorrhizal Fungi, Soil, Diversity, Crop Rotation

\section{Introduction}

Arbuscular mycorrhizal fungi (AMF) are obligate root symbionts which establish associations with the majority

How to cite this paper: Magurno, F., Sasvári, Z., Barchi, L. and Posta, K. (2014) From Monoculture to Norfolk System: How the Number of Crops in Rotation Can Influence the Biodiversity of Arbuscular Mycorrhiza Assemblages in the Soil. Open Journal of Ecology, 4, 1080-1088. http://dx.doi.org/10.4236/oje.2014.417088 
of land plant species [1]. Most of agricultural crops have the potential to host AMF with productivity benefits derived from improved nutrient uptake, in particular phosphate. Furthermore AM fungi can provide increased resistance to soil pathogens and to abiotic stresses such as drought, salinity and heavy metal toxicity, and contribute in improving soil structure [2]-[4]. Due to the high value for agricultural ecosystem functioning and sustainability, AM fungi have drawn the attention for several decades as biological alternatives to chemicals in low-input agriculture [5].

For a profitable capitalization of these symbiota a better understanding of which mechanisms influence the dynamics inside an AMF community is therefore required. Particular attention has been given to the factors provoking reduction of AMF diversity with consequent limitation of complementary benefits provided by different AMF species or genotypes. Chemical fertilization and, above all, high phosphorus levels do not favor a wide AMF community because these conditions can suppress root colonization and thus growth of AMF [6]. Furthermore also other agricultural practices like mechanical disturbance and pesticide application can affect the occurrence of AMF, impacting soil biological activity [7] [8]. Most of AMF community analyses have been exclusively focused on roots, without considering that the extra-radical phase is at least as important as the intraradical mycelia for the nutrient supply of the host plant [9].

Crop rotation is an agronomic practice that exhibits general beneficial aspects associated with maintenance or improvement of soil fertility, reduction in erosion potential and in the build-up of pests and decreased reliance on agricultural chemicals. The effects of crop rotation on the AMF communities are still partially investigated and most of the available data concern morphological aspects as rate of roots colonization and spore abundance [10] [11], in general affected by the identity of host plants involved in the rotation.

In the present work we propose to compare, by means of molecular tools, the effect of different crop rotation practices on the biodiversity and structure of the resident soil AMF communities.

\section{Materials and Methods}

\subsection{Study Site and Sampling}

The sampling site was located at Martonvásár $\left(47^{\circ} 21^{\prime} \mathrm{N}, 18^{\circ} 49^{\prime} \mathrm{E}\right)$, Hungary, where an experimental field was established in 1958 by the Agricultural Research Institute of the Hungarian Research Academy of Sciences. The area was marked by continental climate with an annual rainfall average up to $539 \mathrm{~mm}$ and an annual temperature average of $10.6^{\circ} \mathrm{C}$ (data between 1958 and 2008). The soil was classified as humus loam of the chernozem type with forest residues (21\% clay, 48\% silt and 18\% sand content), slightly acidic in the ploughed layer (pH 6 - 7), with poor supplies of available phosphorus and good supplies of potassium. The experimental area was split into small parcels $(14 \times 7 \mathrm{~m})$ for the different agricultural land use systems in relation to the crop rotation type. Each parcel was characterized by a conventional annual tillage of 20-cm depth and by receiving no fertilization year after year. Weeds and insects were controlled by pesticide treatments as Force (tephlutrine $1.2 \mathrm{lha}^{-1}$ ), Acenit A 880 EC (acetochlore $2.0 \mathrm{lha}^{-1}$ ), and a combination of Motivell (nicosulfuron) + Cambio (dicamba + bentason) + Dach HC surfactant $\left(0.8+2.0+0.6 \mathrm{ha}^{-1}\right)$ used since 1995 as pre-sowing, pre-emergence, and post-emergence treatments, respectively.

Four crop rotation systems were chosen for sampling: maize monoculture (C1), maize and legume (C3: 3 y alfalfa and 5 y maize), maize and wheat (C5: 2 y maize and 2 y wheat), Norfolk type rotation (C7: 1 y maize, 1 y spring barley, $1 \mathrm{y}$ pea, $1 \mathrm{y}$ wheat). Two parcels for each rotation system, at least $40 \mathrm{~m}$ distant, were used for sampling.

Three soil cores $(\sim 5 \times 5 \times 30 \mathrm{~cm})$ were randomly collected from each parcel on June 2012. In total 24 soil samples were collected ( 4 rotation systems $\times 2$ parcels $\times 3$ soil cores).

\subsection{Molecular Analyses}

DNA extraction from $0.5 \mathrm{~g}$ of soil samples was performed using a FastDNA Spin for Soil Kit (Q-BIOgene, Heidelberg, Germany) according to the manufacturer's protocol.

Amplification of LSU fragments (portion of 28S rDNA) was achieved by means of a nested approach with Phusion High Fidelity DNA Polymerase (Fermentas), using LR1 (5'-GCATATCAATAAGCGGAGGA-3') and NDL22 (5'-TGGTCCGTGTTTCAAGACG-3') as outer primers [12] [13] in combination with the inner primers 28G1 (5'-CATGGAGGGTGAGAATCCCG-3') and 28G2 (5'-CCATTACGTCAACATCCTTAACG-3'), specific 
for arbuscular mycorrhizal fungi [14]. PCR was carried out in $40 \mathrm{ul}$ final volume, in a reaction mix according to Phusion High Fidelity DNA Polymerase protocol. Annealing temperatures $\left(62^{\circ} \mathrm{C}\right.$ for the first PCR and $67^{\circ} \mathrm{C}$ for the nested PCR) were calculated using the Tm calculator and instructions on Fermentas website

(http://www.thermoscientific.com/pcrwebtools). PCR products of the expected size ( $585 \mathrm{bp)}$ were purified from agarose gel with GFX PCR DNA and Gel Band Purification Kit (GE Healthcare). Fragments were cloned into CloneJet PCR Cloning Kit (Fermentas) and transformed into Escherichia coli DH5 $\alpha$. Positive transformants were checked by PCR with 28G1-28G2 for the presence and size of the insert. Twenty positive clones per transformation (480 clones totally) were sent to Beckman Coulter Genomics (United Kingdom) for plasmid extraction and sequencing.

\subsection{Editing, Phylogenetic Analysis and Rarefaction Curves}

Sequence similarities were determined using the BLASTn sequence similarity search tool provided by GenBank. Sequences were also checked for chimeras using the "chimera.slayer" command in Mothur v.1.33.3 [15]. Only sequences belonging to Glomeromycota were selected for the subsequent analyses and the others were discarded. Sequence editing was conducted manually using MEGA 6.06 and Chromas Lite 2.01. The sequences were deposited at the National Centre for Biotechnology Information (NCBI) GenBank with accession numbers KM879479KM879872.

LSU sequences were aligned through the CIPRES web-portal with MAFFT on XSEDE and clustered by Mothur into Molecular Operational Taxonomic Units (MOTUs) at the conventional 97\% similarity level, adopted for the definition of a microbial "species" [16]. The representative sequences ("get.oturep" command in Mothur) for each MOTU were used to identify by BLAST reference sequences for phylogenetic analyses.

MEGA 4.0 software assessing Kimura-2p model as distance method and 1000 replicates of non-parametric bootstrap-ping was used to construct a neighbor-joining (NJ) consensus tree. Rarefaction curves, non-parametric richness indices (ACE and Chao1) and Shannon diversity index were estimated with Mothur in order to analyze the $\alpha$-diversity of AMF community in each crop rotation trial.

\subsection{Statistical Analyses}

The obtained data about MOTU distribution were subjected to principal component analysis (PCA) and common components coefficients, eigenvalues and the proportion of the total variance expressed by each single MOTU were calculated. For the analyses the sequences were clustered also in MOTUs with $94 \%$ and $90 \%$ as cutoff of similarity to highlight possible effects at taxonomic rank above species level. The scree plot was used to select the components most relevant for the ordination analysis. Correlations between MOTUs and each principal component were calculated, and those having an absolute value $>0.5$ were considered relevant [17]. A Hierarchical Clustering on Principal Components (HCPC) analysis was performed to define a set of clusters based on MOTUs identified. The cluster analysis was performed only on the most significant PCA components, with the remaining minor ones considered to represent noise. Only dimensions having an eigenvalue $>1$ (Kaiser's method) were considered. The hierarchical clustering was performed according to the Ward criterion, based on variance evaluation (inertia) as well as on the principal component method. The above analyses were implemented with R software.

Canonical Correspondence Analysis (CCA) was run using PAST version 2.16 to relate the abundance of phylospecies to environmental variables. In the assay the $\mathrm{pH}$, humus percentage, total nitrogen, calcium, phosphorus and potassium content of the soil were taken in account.

\section{Results and Discussion}

DNA was extracted successfully from all the soil samples with an average yield of $36 \mathrm{ng} \cdot \mathrm{ul}^{-1}$. All soil DNA samples gave positive PCR products after the nested amplification. Overall 480 clones were sequenced and, after BLASTn analyses, 394 AMF sequences (82\%) were obtained for further analyses. The primer 28G1-28G2 proved to be highly specific because only $1 \%$ of sequences was found to correspond to non-AMF species. According to the BLASTn results $100 \%$ of AMF sequences belonged to the former Glomus group A, corresponding to the family of Glomeraceae in the classification by Redecker et al. [18]. This outcome could be explained by the predominance of Glomeraceae in arable system due to their disturbance-tolerant and opportunistic behavior 
[19].

AMF sequences were clustered, after editing, in 26 MOTUs by Mothur, ranked according to the abundance of sequences (Table 1). The representative sequences for each MOTU were used to build a phylogenetic tree (Figure 1) with the reference sequences identified by BLASTn.

Considering the relative abundance of the MOTUs and their position in the phylogenetic tree, $43 \%$ of sequences belonged to Rhizophagus-Sclerocystis clade (former Glomus Group Ab), 31\% to Funneliformis-Septoglomus clade (former Glomus Group Aa) while the remaining 23\% to Glomus species of uncertain affiliation clustering basal in the Glomeraceae. The latter are very common in environmental studies [20] and probably represent separate genera that cannot yet be defined due to rare or lacking sporulation [21] [22]. The two most abundant MOTUs, representing together about $26 \%$ of total AMF sequences, belonged phylogenetically to the Rhizophagus irregularis clade. Such species is known to be widespread generalists, detected in a range of habitats, colonizing a number of different plant species [23]. Supporting the generalist behavior, the two MOTUs were found in all the treatments. The second phylotype in order of abundance (about $12 \%$ of total sequences) was Funneliformis mosseae (MOTU 03, 17, 24, 25) present as well in all the rotation systems in both parcels. Funneliformis mosseae was found to have a global distribution, potentially related to its spread and successful adaptation to agricultural conditions [24].

Other MOTUs well represented, as MOTU 04 related to Glomus $c f$. diaphanum, MOTUs 05 and 06 related to Glomus species of uncertain affiliation, and MOTU 07 related to Septoglomus viscosum, didn't show a distribution among all the treatments (considering both parcels) neither were found to be characteristic of specific rotation systems.

A Canonical Correlation Analysis was performed to verify whether the differences in composition and structure of the AMF assemblages could be due to the soil properties. However, no significant correlation was found $(P=0.8)$. A Principal Component Analysis (PCA) was performed to investigate a correlation between crop rotation types and relative AMF communities detected. When the analysis was carried out using the MOTUs with 97\% of similarity cutoff as input, no correlation was found (Figure 2).

The analysis was repeated using MOTUs with $94 \%$ and $90 \%$ of similarity cutoff to seek a possible effect of crop rotation system on the AMF communities at a taxonomic rank above species level. In both cases the PCA and the hierarchical clustering did not highlighted a correlation between treatments and the related AMF assemblages (data not shown). The lack of correlation could be related to the findings of several studies where, beside niche-based mechanisms [7] [25], was emphasized the importance of stochastic-neutral processes involved in the shaping of AMF communities [26] [27].

The rarefaction curves (Figure 3), non-parametric richness (ACE and Chao1) and Shannon diversity indices were estimated for the two parcels of each rotation type (Table 2). In maize monoculture (C1-1 and C1-2) and in the first parcel of maize-wheat rotation (C5-1) the curves were close to reach the asymptote while in the first

Table 1. Relative abundance of MOTUs described for each rotation type and parcel. In the first row above, in bold, are indicated the MOTUs (M1, M2...), in the first column on the left the rotation type and parcel. C1: maize monoculture; C3: rotation maize-legume; C5: rotation maize wheat; C7: Norfolk type rotation. The MOTU 18 - 26 are not represented because of the low number of sequences. The values of abundance per each parcel are given in percentage on the total number of sequences available for the parcel.

\begin{tabular}{|c|c|c|c|c|c|c|c|c|c|c|c|c|c|c|c|c|c|}
\hline & M1 & M2 & M3 & M4 & M5 & M6 & M7 & M8 & M9 & M10 & M11 & M12 & M13 & M14 & M15 & M16 & M17 \\
\hline C1-1 & 10.4 & 14.6 & 2.1 & 0 & 0 & 0 & 33.3 & 0 & 0 & 16.7 & 4.2 & 4.2 & 0 & 2.1 & 0 & 0 & 0 \\
\hline C1-2 & 5.7 & 11.3 & 3.8 & 15.1 & 0 & 47.2 & 0 & 5.7 & 0 & 0 & 9.4 & 0 & 0 & 0 & 0 & 1.9 & 0 \\
\hline C3-1 & 0 & 14 & 4 & 4 & 18 & 0 & 8 & 10 & 0 & 4 & 0 & 18 & 14 & 0 & 0 & 0 & 0 \\
\hline C3-2 & 2.3 & 11.6 & 0 & 44.2 & 27.9 & 0 & 0 & 2.3 & 0 & 0 & 0 & 0 & 0 & 0 & 4.7 & 0 & 2.3 \\
\hline C5-1 & 35.2 & 3.7 & 5.6 & 0 & 20.4 & 0 & 1.9 & 5.6 & 0 & 0 & 3.7 & 0 & 0 & 3.7 & 1.9 & 3.7 & 0 \\
\hline C5-2 & 7.5 & 30 & 2.5 & 0 & 0 & 0 & 2.5 & 22.5 & 0 & 0 & 5 & 0 & 0 & 15 & 10 & 2.5 & 0 \\
\hline C7-1 & 0 & 2.1 & 68.1 & 0 & 2.1 & 0 & 2.1 & 0 & 0 & 12.8 & 0 & 0 & 4.3 & 0 & 0 & 2.1 & 4.3 \\
\hline C7-2 & 37.3 & 13.6 & 3.4 & 10.2 & 0 & 0 & 1.7 & 0 & 28.8 & 0 & 0 & 0 & 0 & 0 & 0 & 1.7 & 1.7 \\
\hline
\end{tabular}




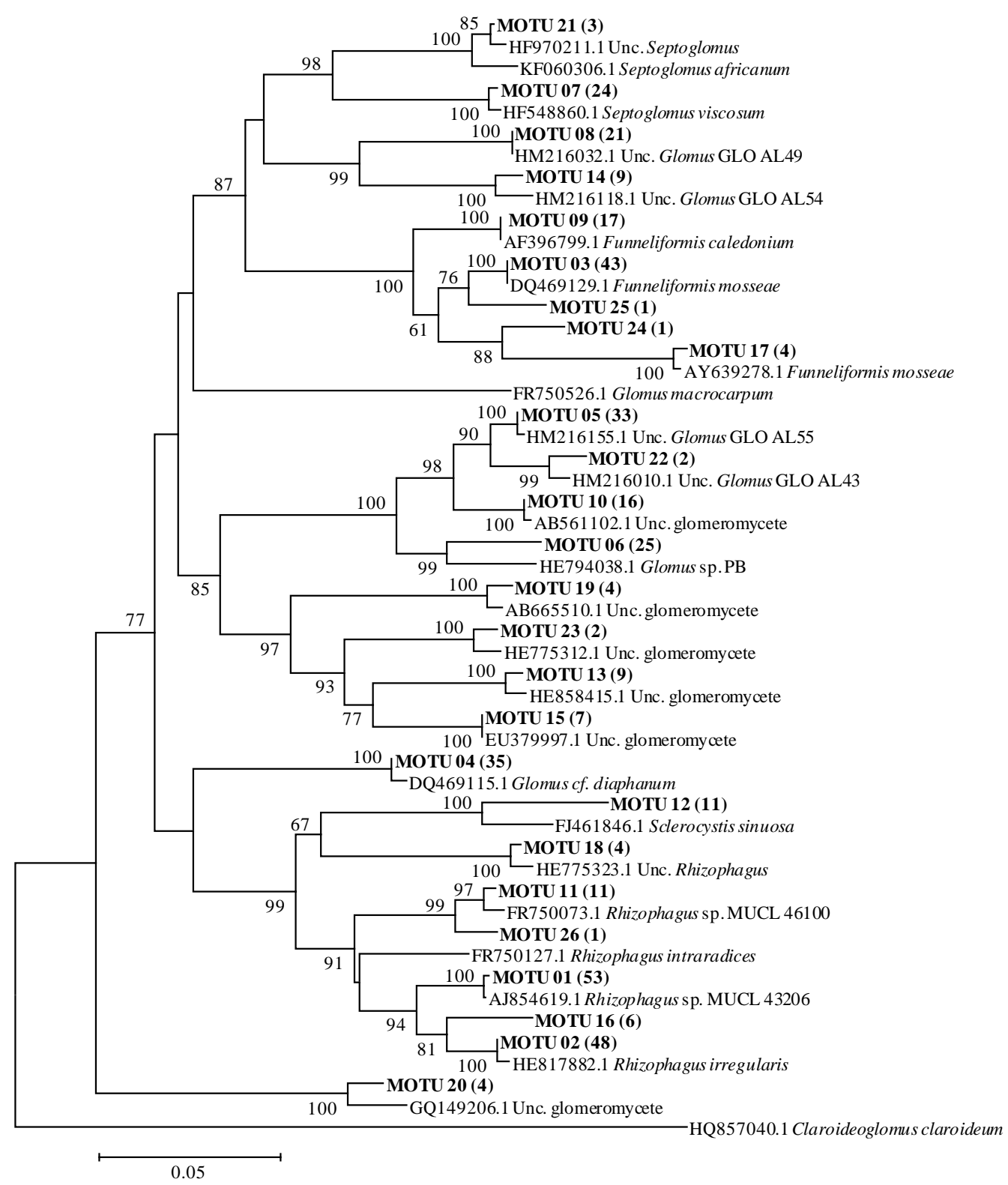

Figure 1. Neighbor-joining tree showing the phylogenetic relationships among MOTUs and reference sequences (25) selected from GenBank. Numbers next the nodes indicate the bootstrap values (above 60\%, 1000 replicates) of the neighbor-joining analysis. Numbers in brackets indicate the sequences clustering in the MOTUs. Claroideoglomus claroideum HQ857040.1 was used to root the tree.

parcel of maize-legume rotation (C3-1) all the MOTUs predicted by the non-parametric richness estimators ACE and Chao1 had been collected by the sampling effort. On the contrary in the Norfolk type rotation (C7) less than the $60 \%$ of MOTUs predicted resulted represented by the sequences analyzed.

The true diversity, measured as effective number of taxa [28], rather than Shannon index, might highlight better a hypothetical influence of the crops succession on the AMF community. AMF are characterized in fact by different strategies of root colonization and development of extraradical mycelium [29] in addiction to seasonality and rate of sporulation [11]. Considering for example the small amount of soil used in the DNA extraction the presence of few spores (high content of DNA) could modify easily the relative abundance of the MOTUs detected in the further analysis and then the Shannon index calculated on the basis of composition and relative abundance of the species. According to number of MOTUs estimated, the diversity decreased from maize mo- 


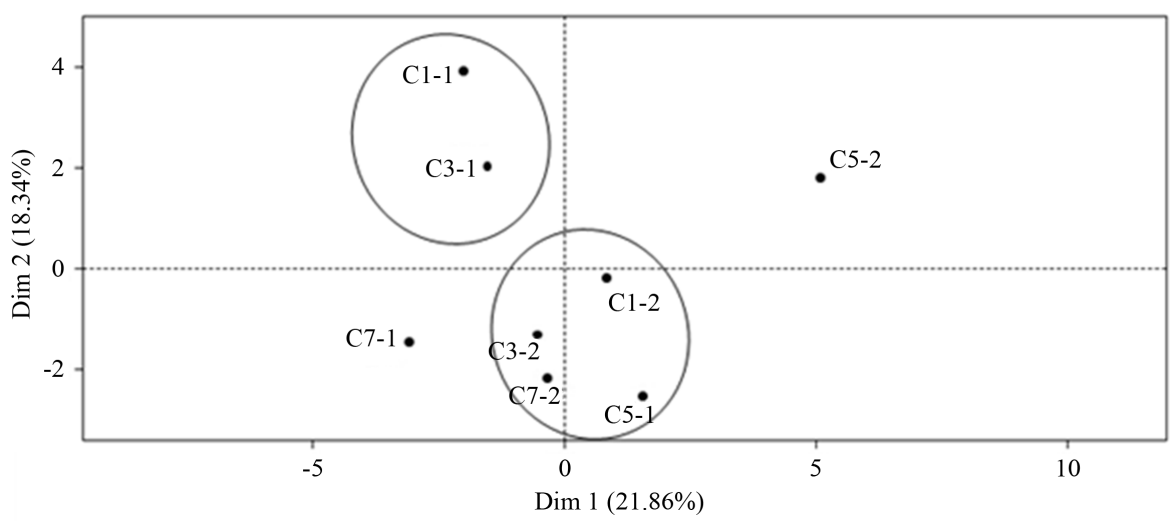

Figure 2. PCA scores for rotation treatments. The PCA scree plot showed that $62.23 \%$ of the overall variation was captured by the first three principal components (PC's). The first PC explained $24.9 \%$ of the variance while the second PC explained $19.68 \%$ of the variance. The analyses, performed using MOTUs with $97 \%$ of similarity as cutoff, shows that the parcels from the same treatment do not tend to cluster together. The circles comprise parcels of similar AMF assemblages according to the cluster analysis.

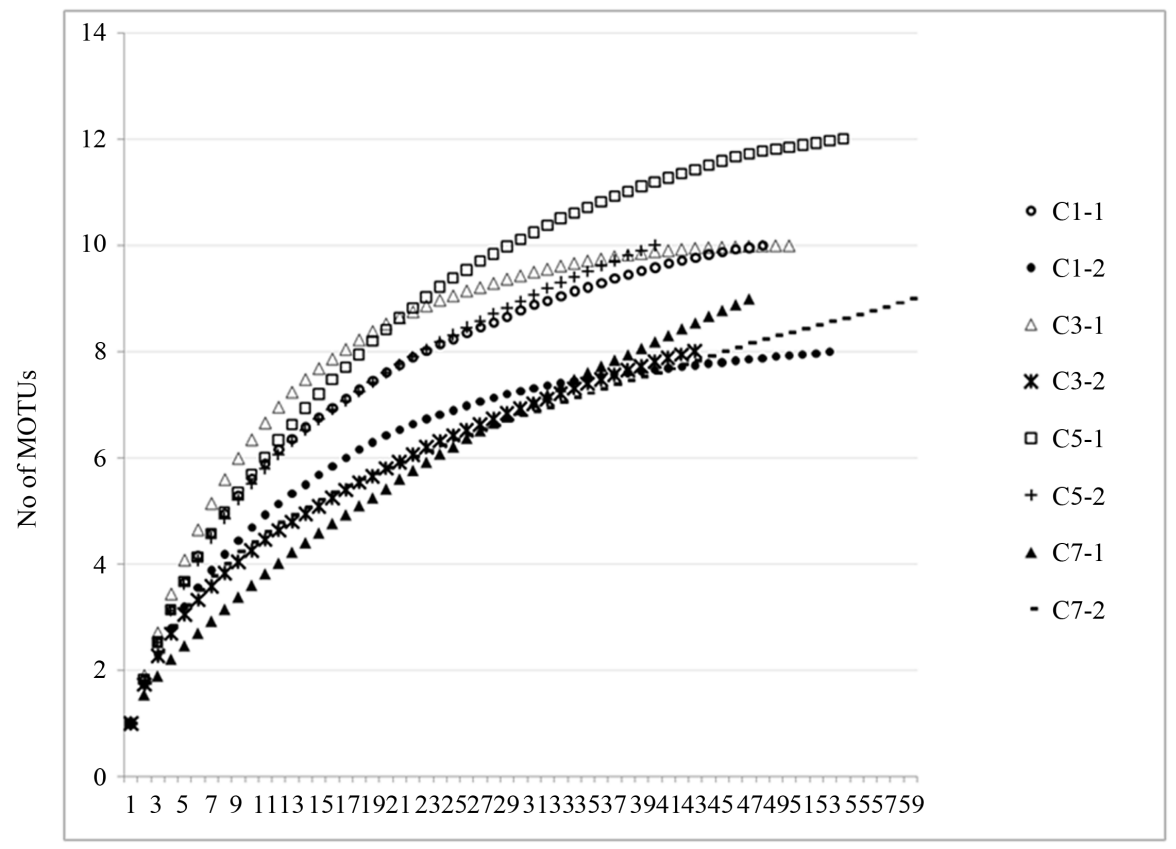

No of sequences

Figure 3. Rarefaction curves showing the sequences sampling effort of this study at a molecular operational taxonomic unit (MOTU) threshold level of $97 \%$ sequence similarity. Open and closed circles represent MOTUs detected in C1-1 and C1-2 respectively (maize monoculture), open triangles and asterisks represent MOTUs in C3-1 and C3-2 (maize-legume), open squares and crosses the MOTUs in C5-1 and C5-2 (maize-wheat), close triangles and dashes the MOTUs in C7-1 and C7-2 (Norfolk type).

noculture (C1), with 8.2 - 10.7 MOTUs predicted, to Norfolk type rotation (C7), with 15 - 15.5 MOTUs predicted, highlighting an effect of the number of crops in succession on the AMF communities. Higo et al. [30] came to a similar conclusion comparing the AMF assemblages in the soil associated to soybean-wheat rotation and to soybean monocropping.

One explanation could be given considering a certain host plant preference by AMF [31] [32] and a moderate soil disturbance (no fertilization, conventional annual tillage of 20-cm depth) characterizing the experimental 
Table 2. Observed versus estimated MOTUs, based on ACE and Chao1 non-parametric richness estimators, and Shannon-Weaver diversity index $\left(H^{\prime}\right)$. Maize monoculture $(\mathrm{C} 1)$, maizealfalfa (C3), maize-wheat (C5) and Norfolk type rotation (C7) were analyzed in two separated parcels per rotation type $(-1$ and -2$)$.

\begin{tabular}{ccccccc}
\hline \multirow{2}{*}{$\begin{array}{c}\text { Crop } \\
\text { rotation }\end{array}$} & $\begin{array}{c}\text { Observed } \\
\text { MOTUs }\end{array}$ & \multicolumn{3}{c}{ Estimated MOTUs } & & Diversity index \\
C1-1 & 10 & 11.18 & 10.25 & 10.71 & 0.93 & 2.19 \\
C1-2 & 8 & 8.39 & 8.00 & 8.20 & 0.98 & 1.89 \\
C3-1 & 10 & 10.00 & 10.00 & 10.00 & 1.00 & 2.32 \\
C3-2 & 8 & 11.82 & 9.00 & 10.41 & 0.77 & 1.80 \\
C5-1 & 12 & 12.91 & 12.20 & 12.55 & 0.96 & 2.30 \\
C5-2 & 10 & 14.82 & 13.00 & 13.91 & 0.72 & 2.19 \\
C7-1 & 9 & 17.75 & 12.33 & 15.04 & 0.60 & 1.58 \\
C7-2 & 9 & 19.00 & 12.00 & 15.50 & 0.58 & 1.85 \\
\hline
\end{tabular}

${ }^{\mathrm{a}} \mathrm{O} / \mathrm{E}=$ No. MOTUs observed divided by No. MOTUs estimated (average value between the two non-parametric richness estimators ACE and Chao1).

field used for sampling. Such agrotechnical regime could have facilitated the durability of AMF inocula in the soil, even in absence of the "optimal" host for some of them. From this point of view the Norfolk type rotation could have been favored in the accumulation of more diversity both for the higher number of crops in succession and for the shorter time between a crop and the following.

\section{Conclusion}

In conclusion, the present study represents the most extended molecular analysis on the effect of different crop rotations on the AMF assemblages in the soil. According to the molecular evidence, crop rotation practice seems to affect the AMF community. The differences in species composition and structure between AMF communities, dominated largely by widespread generalists such as Rhizophagus irregularis and Funneliformis mosseae, appeared due to stochastic reasons. Nevertheless a clear trend regarding the "true diversity", decreasing from Norfolk type to monoculture AMF community, was detected, suggesting the number of crops in rotation among the factor drivers of AMF community shaping.

\section{Acknowledgements}

This study was supported by grants from the National Research Council (OTKA K101878) and from KTIA (AIK_12-1-2012-0012).

\section{References}

[1] Smith, S.E. and Read, D.J. (2008) Mycorrhizal Symbiosis. 3rd Edition, Academic Press, London.

[2] Jeffries, P., Gianinazzi, S., Perotto, S., Turnau, K. and Barca, J.M. (2003) The Contribution of Arbuscular Mycorrhizal Fungi in Sustainable Maintenance of Plant Health and Soil Fertility. Biology and Fertility of Soils, 37, 1-16.

[3] Wright, S.F., Green, V.S. and Cavigelli, M.A. (2007) Glomalin in Aggregate Size Classes from Three Different Farming Systems. Soil \& Tillage Research, 94, 546-549. http://dx.doi.org/10.1016/j.still.2006.08.003

[4] Ruiz-Lozano, J.M., Porcel, R. and Aroca, R. (2008) Evaluation of the Possible Participation of Drought-Induced Genes. In: Varma, A., Ed., The Enhanced Tolerance of Arbuscular Mycorrhizal Plants to Water Deficit, Mycorrhiza, Springer-Verlag, Berlin, 185-205.

[5] Atkinson, D., Baddeley, J.A., Goicoechea, N., Green, J., Sánchez-Díaz, M. and Watson, C.A. (2002) Arbuscular Mycorrhizal Fungi in Low Input Agriculture. In: Gianinazzi, S., Schüepp, H., Barea, J.M. and Haselwandter, K., Eds., Mycorrhizal Technology in Agriculture, Birkhäuser, Basel, 211-222. http://dx.doi.org/10.1007/978-3-0348-8117-3 17

[6] Verbruggen, E., Van der Heijden, M.G.A., Weedon, J.T., Kowalchuk, G.A. and Röling, W.F.M. (2012) Community 
Assembly, Species Richness and Nestedness of Arbuscular Mycorrhizal Fungi in Agricultural Soils. Molecular Ecology, 21, 2341-2353. http://dx.doi.org/10.1111/j.1365-294X.2012.05534.x

[7] Sasvári, Z., Hornok, L. and Posta, K. (2011) The Community Structure of Arbuscular Mycorrhizal Fungi in Roots of Corn Grown in a 50-Year Monoculture. Biology and Fertility of Soils, 47, 167-176. http://dx.doi.org/10.1007/s00374-010-0519-z

[8] Borriello, R., Lumini, E., Girlanda, M., Bonfante, P. and Bianciotto, V. (2012) Effects of Different Management Practices on Arbuscular Mycorrhizal Fungal Diversity in Maize Fields by a Molecular Approach. Biology and Fertility of Soils, 48, 911-922. http://dx.doi.org/10.1007/s00374-012-0683-4

[9] Horton, T.R., and Bruns, T.D. (2001) The Molecular Revolution in Ectomycorrhizal Ecology: Peeking into the BlackBox. Molecular Ecology, 10, 1855-1871. http://dx.doi.org/10.1046/j.0962-1083.2001.01333.X

[10] Mathimaran, N., Ruh, R., Jama, B., Verchot, L., Frossard, E. and Jansa, J. (2007) Impact of Agricultural Management on Arbuscular Mycorrhizal Fungal Communities in Kenyan Ferralsol. Agriculture, Ecosystems \& Environment, 119, 22-32. http://dx.doi.org/10.1016/j.agee.2006.06.004

[11] Oehl, F., Sieverding, E., Ineichen, K., Mäder, P., Wiemken, A. and Boller, T. (2009) Distinct Sporulation Dynamics of Arbuscular Mycorrhizal Fungal Communities from Different Agroecosystems in Long-Term Microcosms. Agriculture, Ecosystems \& Environment, 134, 257-268. http://dx.doi.org/10.1016/j.agee.2009.07.008

[12] van Tuinen, D., Zhao, B. and Gianinazzi-Pearson, V. (1998) PCR in Studies of AM Fungi: From Primers to Application. In: Varma, A., Ed., Mycorrhiza Manual, Springer, Heidelberg, 387-399. http://dx.doi.org/10.1007/978-3-642-60268-9_24

[13] van Tuinen, D., Jacquot, E., Zhao, B., Gollotte, A. and Gianinazzi-Pearson, V. (1998) Characterization of Root Colonization Profiles by a Microcosm Community of Arbuscular Mycorrhizal Fungi Using 25S rDNA-Targeted Nested PCR. Molecular Ecology, 7, 879-887. http://dx.doi.org/10.1046/j.1365-294x.1998.00410.x

[14] da Silva, G.A., Lumini, E., Maia, L.C., Bonfante, P. and Bianciotto, V. (2006) Phylogenetic Analysis of Glomeromycota by Partial LSU rDNA Sequences. Mycorrhiza, 16, 183-189. http://dx.doi.org/10.1007/s00572-005-0030-9

[15] Schloss, P.D., Westcott, S.L., Ryabin, T., Hall, J.R., Hartmann, M., Hollister, E.B., et al. (2009) Introducing Mothur: Open-Source, Platform-Independent, Community-Supported Software for Describing and Comparing Microbial Communities. Applied and Environmental Microbiology, 75, 7537-7541. http://dx.doi.org/10.1128/AEM.01541-09

[16] Rosselló-Mora, R. and Amann, R. (2001) The Species Concept for Prokaryotes. FEMS Microbiology Reviews, 25, 3967. http://dx.doi.org/10.1016/S0168-6445(00)00040-1

[17] Cericola, F., Portis, E., Toppino, L., Barchi, L., Acciarri, N., Ciriaci, T., et al. (2013) The Population Structure and Diversity of Eggplant from Asia and the Mediterranean Basin. PLOS ONE, 8, e73702. http://dx.doi.org/10.1371/journal.pone.0073702

[18] Redecker, D., Schüssler, A., Stockinger, H., Stürmer, S.L., Morton, J.B. and Walker, C. (2013) An Evidence-Based Consensus for the Classification of Arbuscular Mycorrhizal Fungi (Glomeromycota). Mycorrhiza, 23, 515-531. http://dx.doi.org/10.1007/s00572-013-0486-y

[19] Ijdo, M., Schtickzelle, N., Cranenbrouck, S. and Declerck, S. (2010) Do Arbuscular Mycorrhizal Fungi with Contrasting Life History Strategies Differ in Their Responses to Repeated Defoliation? FEMS Microbiology Ecology, 72, 114122. Http://dx.doi.org/10.1111/j.1574-6941.2009.00829.x

[20] Öpik, M., Vanatoa, A., Vanatoa, E., Moora, M., Davison, J., Kalwij, J.M., Reier, Ü. and Zobel, M. (2010) The Online Database MaarjAM Reveals Global and Ecosystemic Distribution Patterns in Arbuscular Mycorrhizal Fungi (Glomeromycota). New Phytologist, 188, 223-241. http://dx.doi.org/10.1111/j.1469-8137.2010.03334.X

[21] Sanders, I.A. (2004) Plant and Arbuscular Mycorrhizal Fungal Diversity-Are We Looking at the Relevant Level of Diversity and Are We Using the Right Techniques? New Phytologist, 164, 415-418. http://dx.doi.org/10.1111/j.1469-8137.2004.01208.x

[22] Rosendahl, S. and Stukenbrock, E.H. (2004) Community Structure of Arbuscular Mycorrhizal Fungi in Undisturbed Vegetation Revealed by Analyses of LSU rDNA Sequences. Molecular Ecology, 13, 3179-3186. http://dx.doi.org/10.1111/j.1365-294X.2004.02295.x

[23] Öpik, M., Moora, M., Liira, J. and Zobel, M. (2006) Composition of Root-Colonizing Arbuscular Mycorrhizal Fungal Communities in Different Ecosystems around the Globe. Journal of Ecology, 94, 778-790. http://dx.doi.org/10.1111/j.1365-2745.2006.01136.x

[24] Rosendahl, S., McGee, P. and Morton, J.B. (2009) Lack of Global Population Genetic Differentiation in the Arbuscular Mycorrhizal Fungus Glomus mosseae Suggests a Recent Range Expansion Which May Have Coincided with the Spread of Agriculture. Molecular Ecology, 18, 4316-4329. http://dx.doi.org/10.1111/j.1365-294X.2009.04359.x

[25] Balestrini, R., Magurno, F., Walker, C., Lumini, E. and Bianciotto, V. (2010) Cohorts of Arbuscular Mycorrhizal Fungi (AMF) in Vitis vinifera, a Typical Mediterranean Fruit Crop. Environmental Microbiology Reports, 2, 594-604. 
http://dx.doi.org/10.1111/j.1758-2229.2010.00160.x

[26] Dumbrell, A.J., Nelson, M., Helgason, T., Dytham, C. and Fitter, A.H. (2010) Relative Roles of Niche and Neutral Processes in Structuring a Soil Microbial Community. The ISME Journal, 4, 337-345. http://dx.doi.org/10.1038/ismej.2009.122

[27] Lekberg, Y., Schnoor, T., Kjøller, R., Gibbons, S.M., Hansen, L.H., Al-Soud, W.A., Sørensen, S.J. and Rosendahl, S. (2012) 454-Sequencing Reveals Stochastic Local Reassembly and High Disturbance Tolerance within Arbuscular Mycorrhizal Fungal Communities. Journal of Ecology, 100, 151-160. http://dx.doi.org/10.1111/j.1365-2745.2011.01894.x

[28] Tuomisto, H. (2011) Commentary: Do We Have a Consistent Terminology for Species Diversity? Yes, If We Choose to Use It. Oecologia, 167, 903-911. http://dx.doi.org/10.1007/s00442-011-2128-4

[29] Hart, M.M. and Reader, R.J. (2002) Taxonomic Basis for Variation in the Colonization Strategy of Arbuscular Mycorrhizal Fungi. New Phytologist, 153, 335-344. http://dx.doi.org/10.1046/j.0028-646X.2001.00312.x

[30] Higo, M., Isobe, K., Yamaguchi, M., Ishii, R., Drijber, R.A. and Jeske, E.S. (2013) Diversity and Vertical Distribution of Indigenous Arbuscular Mycorrhizal Fungi under Two Soybean Rotational Systems. Biology and Fertility of Soils, 49, 1085-1096. http://dx.doi.org/10.1007/s00374-013-0807-5

[31] Vandenkoornhuyse, P., Ridgway, K.P., Watson, I.J., Fitter, A.H. and Young, J.P.W. (2003) Co-Existing Grass Species Have Distinctive Arbuscular Mycorrhizal Communities. Molecular Ecology, 12, 3085-3095. http://dx.doi.org/10.1046/j.1365-294X.2003.01967.x

[32] Helgason, T., Merryweather, J.W., Young, J.P.W. and Fitter, A.H. (2007) Specificity and Resilience in the Arbuscular Mycorrhizal Fungi of a Natural Woodland Community. Journal of Ecology, 95, 623-630. http://dx.doi.org/10.1111/j.1365-2745.2007.01239.x 
Scientific Research Publishing (SCIRP) is one of the largest Open Access journal publishers. It is currently publishing more than 200 open access, online, peer-reviewed journals covering a wide range of academic disciplines. SCIRP serves the worldwide academic communities and contributes to the progress and application of science with its publication.

Other selected journals from SCIRP are listed as below. Submit your manuscript to us via either submit@scirp.org or Online Submission Portal.
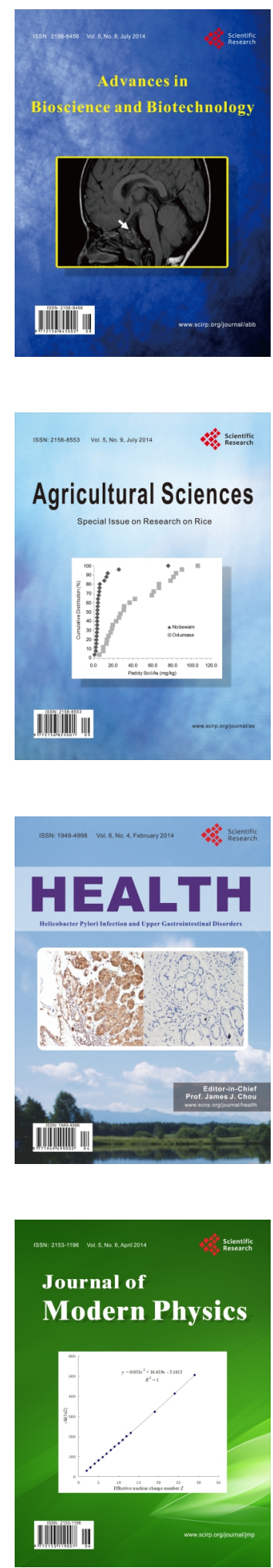
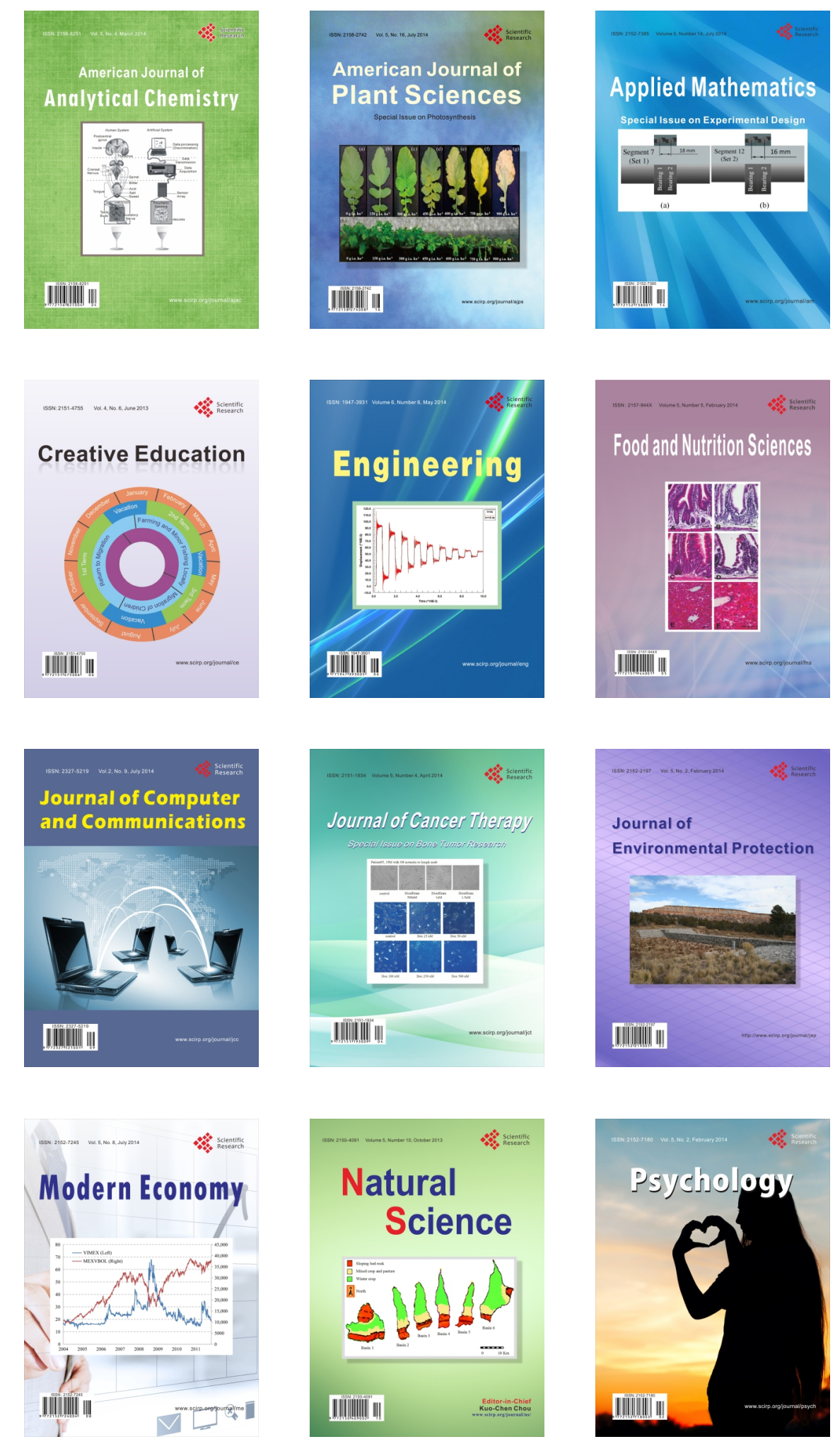